\title{
Pigment Coloration Research Published in the Science Citation Index Expanded from 1990 to 2020: A Systematic Review and Bibliometric Analysis
}

\author{
Mohammad Tajul Islam ${ }^{1, *(\mathbb{D}}$, Mohammad Sahariar Farhan ${ }^{1}$, Farzana Faiza ${ }^{1}$ D, A. F. M. Fahad Halim ${ }^{2}$ \\ and Afsana Al Sharmin ${ }^{3}$ iD \\ 1 Department of Textile Engineering, Ahsanullah University of Science and Technology, 141-142 Love Rd., \\ Tejgaon I/A, Dhaka 1208, Bangladesh; farhansahariar18@gmail.com (M.S.F.); faiza.te@aust.edu (F.F.) \\ 2 Centre for Water, Energy and Waste, Murdoch University, Perth 6150, Australia; \\ 34196474@student.murdoch.edu.au \\ 3 Department of Mathematical and Physical Sciences, East West University, Aftabnagar, Dhaka 1212, \\ Bangladesh; aas@ewubd.edu \\ * Correspondence: tajul.dtt@aust.edu
}

check for

updates

Citation: Islam, M.T.; Farhan, M.S.;

Faiza, F.; Halim, A.F.M.F.; Sharmin, A.A. Pigment Coloration Research Published in the Science Citation Index Expanded from 1990 to 2020: A Systematic Review and Bibliometric Analysis. Colorants 2022, 1, 38-57. https://doi.org/10.3390/ colorants1010005

Academic Editor: Jae-Hong Choi

Received: 25 December 2021

Accepted: 9 February 2022

Published: 14 February 2022

Publisher's Note: MDPI stays neutral with regard to jurisdictional claims in published maps and institutional affiliations.

Copyright: () 2022 by the authors. Licensee MDPI, Basel, Switzerland. This article is an open access article distributed under the terms and conditions of the Creative Commons Attribution (CC BY) license (https:// creativecommons.org/licenses/by/ $4.0 /)$.

\begin{abstract}
A systematic review and bibliometric study were undertaken utilizing the Science Citation Index Expanded database from 1990 to 2020 to obtain insights into the trajectory of pigment coloration research. The study focused on the publication performance in terms of the yearly production and citations, as well as mainstream journals, categories of the Web of Sciences, leading nations, wellknown institutions, and research trends. The survey found that the yearly output of scholarly publications on pigment coloration research climbed gradually throughout the first quarter of the study period and then increased substantially in the latter five years. The present research emphasis and future trends were examined after summarizing the paper title and abstract analyses, author keyword analysis, and the most regularly used keywords derived from words in KeyWords Plus. To expand its reach in numerous application areas, pigment coloration research will continue to focus on improving pigment qualities.
\end{abstract}

Keywords: pigment printing; pigment dyeing; binder; SCI-EXPANDED; Scientometrics; $T_{\text {year }} ; C_{\text {year }}$; $C P P_{\text {year }}$

\section{Introduction}

Any materials that are exerted to a substrate to impart color into it can be referred to as colorants, and the process of application can be referred to as coloration. The most well-known terms for colorants in textile coloration are dyes and pigments [1]. Pigments differ from dyes in their application. The dye usually enters the substrate in a soluble state, whereas a pigment stays as a finely distributed insoluble solid throughout the coloration process. Pigments have no intrinsic substantiveness for the textile substrate [2].

Pigments are white or colored chemicals that can be aromatic organic, organometallic coordination compounds, or insoluble inorganic salts of soluble organic dyes. Some pigments, for instance white titanium dioxide and yellow, brown, and black iron oxides, are inorganic and contain no aromatic carbon. Another type includes carbon black, which is organic but not aromatic [1].

Pigments can be applied to textile fibers in a variety of ways, including printing paste, color baths, and padding liquid. In all cases, one of the most significant elements, the binder, is required to integrate pigment particles into the surface of the fiber and adhere them to the surface via the binder-fiber adhesive force [3]. The binder produces a coating on the fiber that should be colorless, clear, and flexible.

It should be of consistent thickness and smoothness and adhere well to the substrate. When heat-treated, the binder film should not be too hard or too soft, and it should be able 
to withstand mechanical and chemical stresses properly. It should be removed from the printing roller, screen, or blanket as soon as possible during usage [4].

In the printing and coloring industries, pigments are commonly employed. Pigment printing is now the most extensively used textile method because it can be applied to a wide range of fibers and does not require washing after application. According to studies, pigment printing processes roughly $65 \%$ of the world's printed matter [5]. Pigment printing provides several advantages, including strong light resistance, but it is dependent on the binder's quality, adaptability to a variety of fabrics, and color range. Although this is a generally straightforward technological procedure, it does have certain limitations. The drawbacks include a limited standard of wash fastness owing to the absence of any ionic bonding between the pigment print paste and the cotton fabric [6].

Pigment dyeing is thriving and drawing more attention than conventional dyeing. In pigment dyeing, the fabric is chemically treated to be covered with a positive charge so that it can adsorb the negatively charged pigment particles due to the electrostatic attraction. As no chemical reaction occurs between the dyeing solution and the fabric, the pigment is attached to the fabric by the link of a binder. The binder helps in fixation for deep color. The temperature, time, bath ratio, modifier dose, and other aspects have a higher influence on pigment dyeing and should be taken into account [7].

Recently, sustainability and environment-friendly approaches have been emphasized in textile wet processing research, such as sustainable coloration [8], environment-friendly coloration [9-11], and eco-friendly finishing [12]. It would be interesting to see if pigment coloration research also has received similar emphasis. The research on pigment coloration throughout the last three decades was examined to acquire a better grasp of the global research status in this discipline.

This bibliometric study also serves as a foundation for the establishment of medium and long-term pigment coloration research initiatives. Thus, the analysis synthesized quantitative descriptions of publications retrieved from indexed journals, categories by Web of Science, yearly outputs, and top institutions and leading countries as well as the research trends and hotspots identified through the analyses of paper titles, author keywords, and KeyWords Plus. These bibliometric analyses bring together selected pigment coloration findings and their applications in dyeing, printing, and surface modifications of textile materials.

\section{Method}

\subsection{Eligibility Criteria}

This research was designed as a systematic literature review in accordance with the PRISMA statement [13]. The review protocol was registered in the Open Science Framework (OSF) under the following DOI: 10.17605/OSF.IO/QW457 (link: https: / / osf.io/ qw457, accessed on 29 January 2022). Only published peer-reviewed documents were included in this search. The documents had to be published in the English language (or English translation readily available) and had to be published in the last 30 years (from 1 January of 1990 to 31 December 2020). The research work must involve the coloration of textile material using pigment.

\subsection{Search Strategy}

Blinded researchers were randomly paired and assigned by the corresponding author to perform an independent search of database. The data for this present study was obtained from the SCI-EXPANDED of Web of Science in Clarivate Analytics (updated on 19 August 2021). The journal impact factors in 2020 ( $\left(F_{2020}\right)$ were presented on 30 June 2021 in Journal Citation Reports (JCR).

According to the definition of journal impact factor, it is better to collect the documents published in 2020 from the SCI-EXPANDED after $I F_{2020}$ was published. After pre-study, following words were considered as search keywords in SCI-EXPANDED: "pigment dyeing", "pigment dyeings", "pigment coloration", "pigment colorations", "pigment colouration", 
"pigment colourations", "pigment print", "pigment prints", "pigment printing", "pigment printings", "pigment dyed", "pigment printed", "pigment coloured", and "pigment colored". These words were searched by the terms of Topic in the SCI-EXPANDED.

\subsection{Screening of Articles' Titles and Abstracts}

Although SCI-EXPANDED was created primarily for researchers to find and search the literature, it does not present data in a readily available form for bibliometric investigations [14,15]. As a result, data processing is always required for bibliometric studies, followed by data collection directly from SCI-EXPANDED. Recently, a large difference was found by using 'front page', including the paper title, abstract, and author keywords in the paper [16] as a filter in bibliometric studies [17].

KeyWords Plus can enhance and supplement title-word and author-keyword indexing by extracting additional search terms from the titles of publications that are mentioned by authors in their bibliographies and footnotes in the ISI (now Clarivate Analytics) database [18]. It was suggested that documents that could only be searched using KeyWords Plus were unrelated to the topic being searched [19]. Searches using the above-mentioned keywords resulted in 248 documents from 1990 to 2020 . A total of 20 documents $(8.06 \%$ of the 248 documents) did not have search keywords on their 'front page'.

A manual screening of the search results revealed four documents (1.61\%) that were not related to the pigment coloration of textiles. Since the objective was to find the publications dealing with the pigment coloration of textiles, those four articles were excluded. A total of 224 documents were defined as pigment coloration publications. For analysis, these records were imported into a spreadsheet, and additional coding was done manually using Microsoft Excel 2016 [20]. Moreover, each journal's journal impact factor $\left(I F_{2020}\right)$ was acquired from the JCR in 2020. Details regarding the search process can be seen in Figure 1.

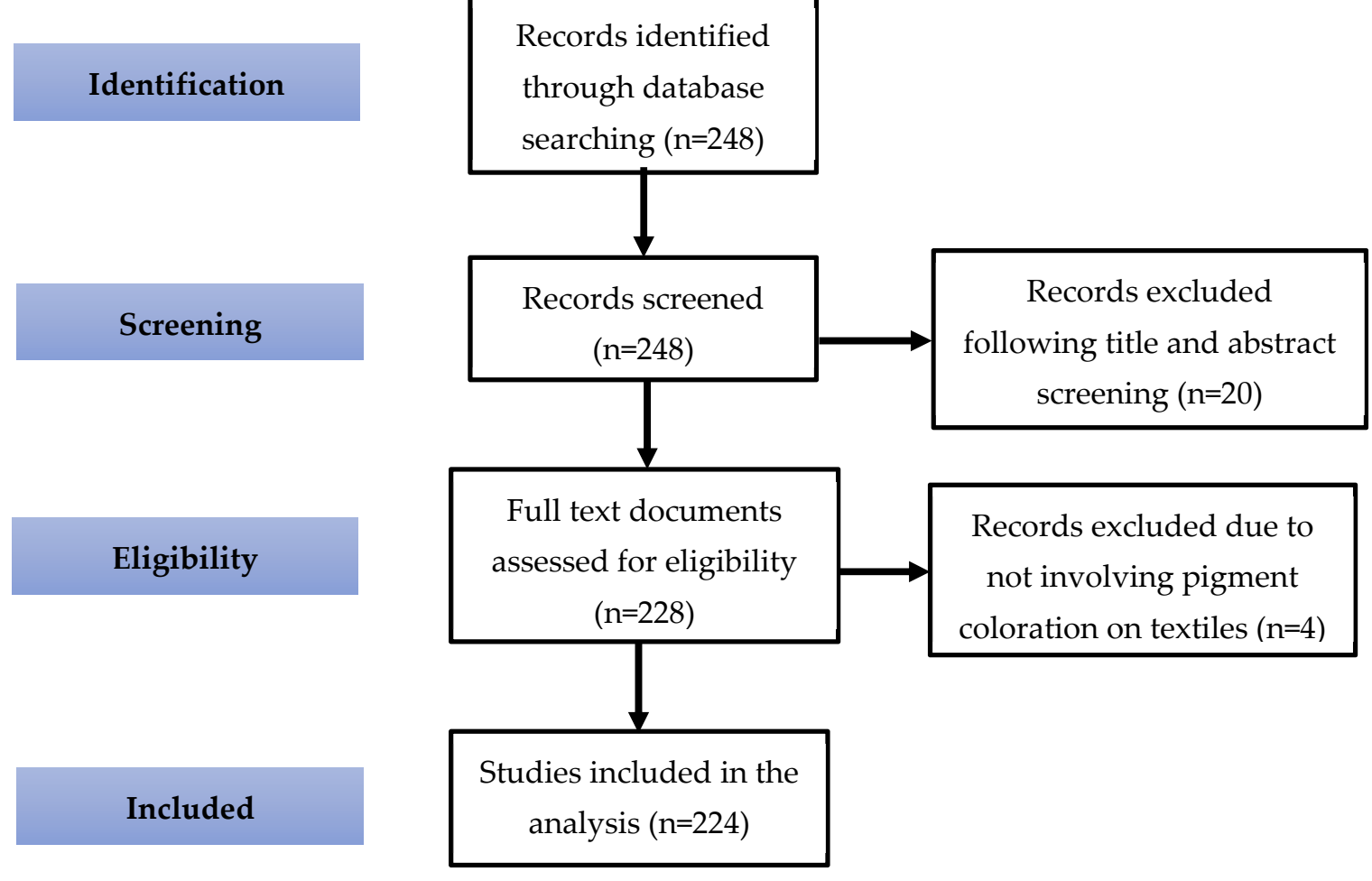

Figure 1. PRISMA Chart by [21] illustrating the article selection process of the systematic review.

SCI-EXPANDED is mainly designed for researchers to find literature but not bibliometric studies [14]. Thus, it is necessary to have a data treatment when using it for a bibliometric study. The corresponding author is marked as a reprint author in SCI- 
EXPANDED; however, we utilized the term corresponding to author in this study [22]. In the case of articles with multiple corresponding authors, only the last corresponding author, institute, and country are designated as corresponding author information [23]. To have accurate analysis results, affiliations originating from England and Scotland were categorized as being from the United Kingdom (UK).

Three citation indicators were used to analyze the citations received by the articles: $C_{\text {year }}$ : the total number of citations in a particular year from the Web of Science Core Collection. $C_{2020}$ means the number of citations in 2020 [22].

$\mathrm{TC}_{\text {year }}$ : the total number of citations from the Web of Science Core Collection since publication year to the end of the most recent year [24]. In this study, the most recent year was $2020\left(T C_{2020}\right)$. $C P P_{\text {year }}$ : the citations per publication $\left(C P P_{2020}=T C_{2020} / T P\right)$ [22], $T P$ is total number of articles.

\section{Results}

\subsection{Document Type and Language of Publication}

In 2004, a connection between document types and citations per publication was proposed [25]. After a decade, the citations per publication were improved by using the citation indicator of CPPyear, which gives more accurate values [26]. In 2017, the number of authors per publication $(A P P)$ was used in the discussion of document types [27]. Table 1 illustrates the characteristics of four document types, including 246 articles $(99.19 \%$ of the 248 documents) with an APP of 3.0 .

Table 1. Citations and authors according to the document type.

\begin{tabular}{ccccccc}
\hline Document Type & $\boldsymbol{T P}$ & $\mathbf{( \% )}$ & $\boldsymbol{A U}$ & $\boldsymbol{A P P}$ & $\boldsymbol{T C}_{\mathbf{2 0 2 0}}$ & $\boldsymbol{C P P}_{\mathbf{2 0 2 0}}$ \\
\hline Article & 190 & 77 & 746 & 4 & 1983 & 10 \\
Book Chapter & 1 & 0.41 & 1 & 1 & 0 & 0 \\
Proceedings Paper & 51 & 21 & 178 & 4 & 87 & 0.4887 \\
Review & 4 & 2 & 11 & 3 & 94 & 24 \\
\hline
\end{tabular}

TP: number of publications; $A U$ : number of authors; $A P P$ : number of authors per publication; $T C_{2020}$ : total number of citations from Web of Science Core Collection since publication year to the end of 2020; $C P P_{2020}$ : number of citations $\left(T C_{2020}\right)$ per publication $(T P)$.

The largest number of authors in an article was in the "Analysis of Samples Excavated from a Royal Tomb in El Zotz: Application of Materials Science Characterization Techniques in Archaeology" [28] published by 11 authors from one institute in the USA. The document type of the Review Article had the highest $C P P_{2020}$ of 23.5, which was a combination of four review articles with a $T C_{2020}$ of 100 or more [29], by Zhang et al. [30] with a $T C_{2020}$ of 60 . The $C P P_{2020}$ of the reviews was 2.3-times the $C P P_{2020}$ of the articles, which is much higher than a new research topic of ultraviolet (UV)-curable water-borne polyurethane acrylate binders at 5.9 times [31].

For pigment coloration, not a single meeting abstract was published in any of the journals. For pigment coloration research, there were no classic publications with $T C_{2020}$ of 1000 or more [32]. The publication that had the highest $T C_{2020}$ was at 74 , which does not even cross 100. "Synthesis of polyurethane acrylate oligomers as aqueous UV-curable binder for inks of ink jet in textile printing and pigment dyeing" [33] had a $T C_{2020}$ of 74. In addition, five of the top ten most-frequently cited publications were reviews in pigment coloration research. It is worth noting that documents in the Web of Science Core Collection can be split into two document types.

For example, five documents were classified as document types of proceedings papers and also articles; thus, the sum of the percentages is greater than $100 \%$ [34]. Only 244 articles that included an introduction, methods and materials, results and discussion, and conclusion were chosen for further analysis out of all document categories. One of the most important considerations in bibliometric research as big data analysis is the language of publishing [24]. English was the predominant language, accounting for 98 percent of 
all articles. Five articles were published in different languages, where two articles were published in Croatian and one each in German, Chinese, and Japanese.

\subsection{Characteristics of Publication Outputs}

A connection between the total annual number of articles $(T P)$ and their citations per publication $\left(C P P y e a r=T C_{\text {year }} / T P\right)$ by year was proposed by Ho to understand publications and their impact trends for a research topic [35]. Figure 2 depicts the year-by-year distribution of $T P$ and their $C P P_{2020}$. This has been used as a unique indicator for widely researched topics-for example, bacterial nanocellulose [36], metal-organic frameworks [37], distributed control [38], child sexual abuse [39], Fenton oxidation for soil and water remediation [34], and artificial intelligence [40]. The annual publication outputs increased sharply during the last six years.

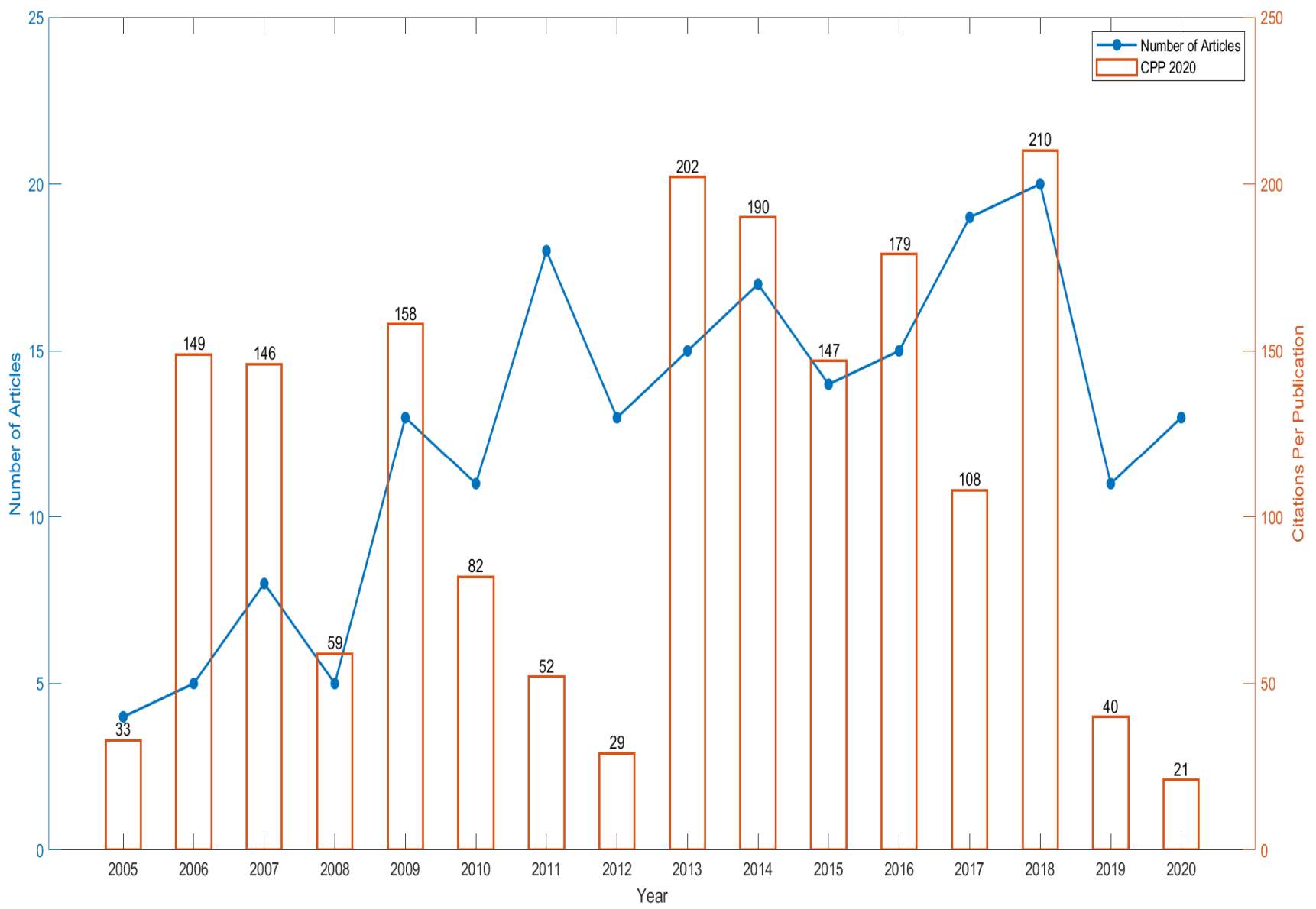

Figure 2. The number of pigment coloration articles and their citations per publication by year.

Pigment coloration has received a great deal of attention in recent years. The mean number of $C P P_{2020}$ was nine. In 2007 , the first article appeared with a $T C_{2020}$ of 74 . Only one highly cited article was published in 2007. In the early years, El-Molla from Natl Res Ctr, Test Res Div, Cairo 12622, Egypt, published the main highly cited articles, including "Synthesis of polyurethane acrylate oligomers as aqueous UV-curable binder for inks of ink jet in textile printing and pigment dyeing" [33] in 2007 with $T C_{2020}$ of 74 (rank first) and "Eco-friendly printing of natural fabrics using natural dyes from alkanet and rhubarb" [41] in 2009 with $T C_{2020}$ of 51 (rank fifth). In 2006, 2007, and 2016, there were one, two, and three articles that had higher $C P P_{2020}$ values of 58,74 , and 60, respectively, which can be attributed to the articles by El-Molla from Natl Res Ctr, Test Res Div, Cairo, Egypt and Zhang's group in Anhui Polytech Univ, Coll Text \& Clothing, Wuhu, the People's Republic of China. 


\subsection{Web of Science Categories and Journals}

In the year 2020, a total of 9500 journals were indexed by JCR across 178 Web of Science categories in SCI-EXPANDED. Recently, a relationship between the number of articles and journals in a Web of Science category as well as the number of authors and citations per publication was proposed [42]. The 244 pigment coloration-related articles were published in a wide range of 195 journals under 38 Web of Science categories in SCI-EXPANDED. In the total 244 articles, 195 articles were published in different journals and the other 49 as proceeding papers, and all of them were classified in SCI-EXPANDED. The top ten Web of Science categories are shown in Table 2.

Table 2. The top 10 productive Web of Science categories.

\begin{tabular}{|c|c|c|c|c|c|c|c|}
\hline Web of Science Category & $T P$ & $(\%)$ & $T C_{2020}$ & $C P P_{2020}$ & $A U$ & $A P P$ & No. $J$ \\
\hline Chemistry (Applied) & 63 & 17.45 & 883 & 14 & 229 & 4 & 62 \\
\hline Chemistry (Multidisciplinary) & 18 & 5 & 55 & 3 & 77 & 4 & 18 \\
\hline Chemistry (Organic) & 11 & 3.04 & 315 & 29 & 46 & 4 & 11 \\
\hline Chemistry (Physical) & 8 & 2.22 & 106 & 13 & 33 & 4 & 8 \\
\hline Chemistry (Engineering) & 50 & 13.85 & 592 & 12 & 174 & 3.5 & 46 \\
\hline Material Science (Textile) & 117 & 32.4 & 955 & 8 & 411 & 3.5 & 89 \\
\hline Material Science (Coating) & 16 & 4.43 & 134 & 8 & 68 & 4 & 16 \\
\hline Material Science (Multidisciplinary) & 27 & 7.48 & 144 & 6 & 99 & 4 & 22 \\
\hline Physics (Applied) & 9 & 2.5 & 142 & 16 & 29 & 3 & 9 \\
\hline Polymer Science & 42 & 11.63 & 551 & 13 & 183 & 4.35 & 41 \\
\hline
\end{tabular}

$T P$ : number of publications; \%: percentage of 244 articles; $T C_{2020}$ : total number of citations from Web of Science Core Collection since publication year to the end of 2020; $C P P_{2020}$ : number of citations $\left(T C_{2020}\right)$ per publication $(T P) ; A U$ : total number of authors; $A P P$ : number of authors per publication; No. J: number of journals in a Web of Science category.

The Web of Science category of Material Science (Textile) was the leading category with 117 articles (47.95\% of 244 articles). Compared to the top 10 categories, pigment coloration articles with the highest $C P P_{2020}$ were published in the category of Chemistry (Organic) with a $C P P_{2020}$ of 29 . In 2020,62 journals were classified in the category of Chemistry (Applied) with 63 articles (25.82\% of 244 articles) ranked second, while nine journals in the category of Applied Physics with nine articles ranked ninth. The category of Polymer Science published 42 articles (ranked seventh; $17.21 \%$ of 244 articles) and had a higher $C P P_{2020}$ of 13.

The average of authors $(A P P)$ in the category of Polymer Science was 4.35, while Material Science (Textiles) was at 3.5. Journals indexed in SCI-EXPANDED can be classified into two or more categories, for example, Carbohydrate Polymers was classified in the categories of Chemistry (Applied), Chemistry (Organic), and Polymer Science; thus, the sum of percentages could be higher than $100 \%$ [29]. Figure 3 shows the development trends of the top five categories with more than 25 articles.

In 1992, the first pigment coloration article was published in Advanced Materials that was classified in the three Web of Science categories: Chemistry (Applied), Engineering (Chemical) and Material Science (Textiles). The first articles in the categories of Material Science (Textiles) and Chemistry (Applied) were published in 1991 and 1992, respectively. The category of Material Science (Textiles) published the majority of pigment coloration articles, especially after 2007.

The top five most productive journals with more than eight articles were: Coloration Technology $\left(I F_{2020}=1.614\right)$ with 15 articles $(6.15 \%$ of 244 articles $)$, Fibers and Polymers $\left(I F_{2020}=2.153\right)$ with 11 articles $(4.5 \%)$, Carbohydrate Polymers $\left(I F_{2020}=9.381\right)$ with 10 articles $(4.0 \%)$, AATCC Review $\left(I F_{2020}=0.125\right)$ with nine articles $(3.7 \%)$ and Dyes and Pigments $\left(I F_{2020}=4.889\right)$ with eight articles $(3.28 \%)$. According to the journal impact factor, Cellulose with four articles, places third with $I F_{2020}$ of 5.044, followed by Applied Surface Science with three articles $\left(I F_{2020}=6.707\right)$, the Journal of Dispersion Science and Technology with four articles $\left(I F_{2020}=2.262\right)$, and Polymer with one article $\left(I F_{2020}=4.430\right)$. 


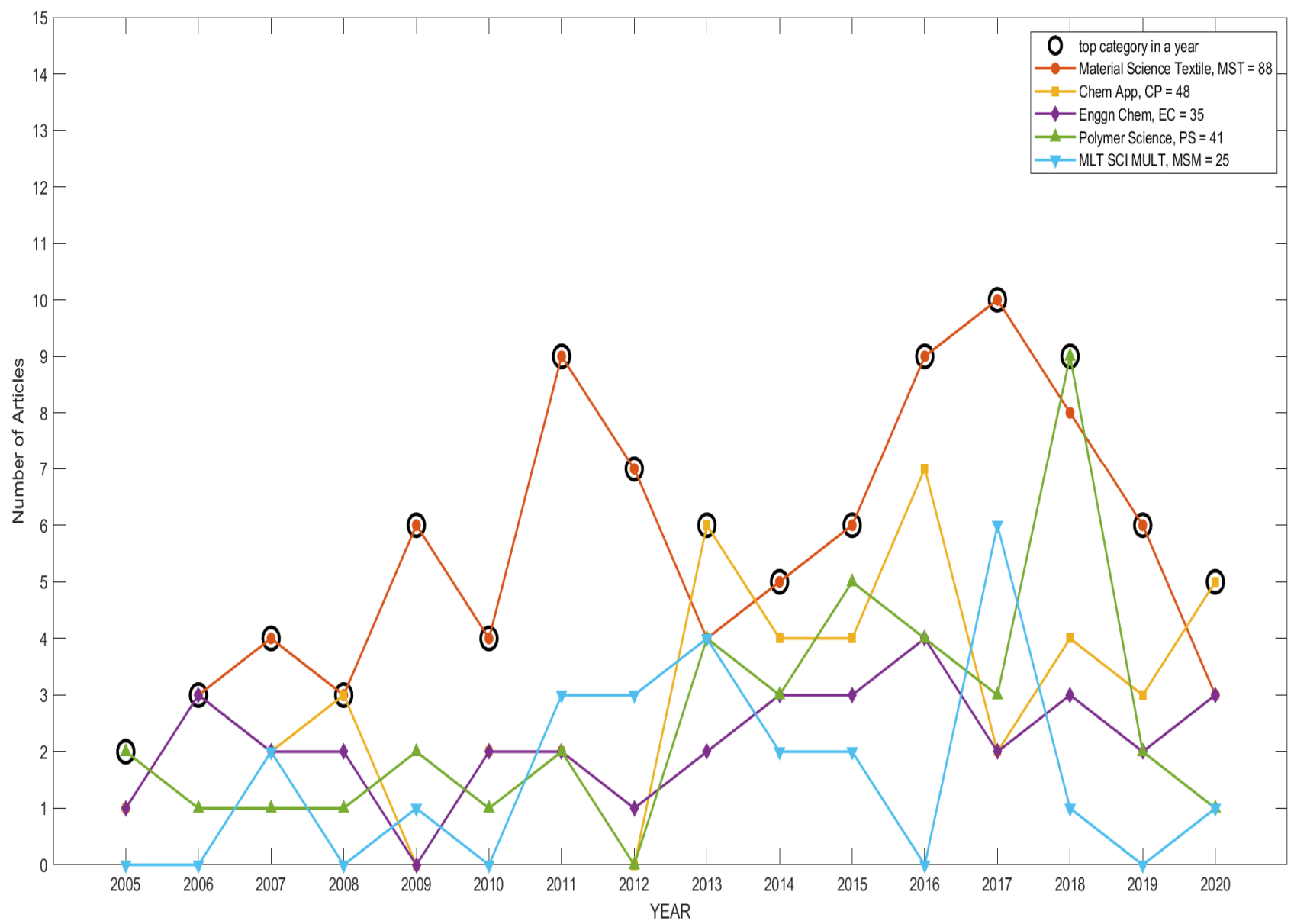

Figure 3. Developments of the top five Web of Science categories with $T P>25$.

\subsection{Publication Performances: Countries and Institutions}

Of the 244 Pigment coloration articles from 32 different countries, 212 articles $(86.88 \%$ of the 244 articles) were single country articles across 23 different countries, while 18 (7.38\%) articles were international collaborations from 24 different countries. The top 10 productive countries are listed in Table 3. Four Asian countries, two Middle Eastern countries, one American country, one country from the UK, Slovenia, and Russia made the top ten list of publications. Outside of the top 10, Thailand and Iran ranked 11th with four articles each followed by Australia, Spain, Malaysia, Croatia, France, and Italy.

Table 3. Top 10 productive countries.

\begin{tabular}{|c|c|c|c|c|c|c|c|c|c|}
\hline Country & $T P$ & $T P R \%$ & $\begin{array}{c}T P \\
C P P_{2020}\end{array}$ & $I P R \%$ & $C P R \%$ & $F P R \%$ & $F P C P P_{2020}$ & $R P R \%$ & $\begin{array}{c}R P \\
C P P_{2020}\end{array}$ \\
\hline China & 78 & 1(36.62) & 5.92 & 1(37.97) & $1(28)$ & $1(38.5)$ & 5.97 & $1(36.32)$ & 5.93 \\
\hline Egypt & 41 & $2(19.25)$ & 17.49 & $2(19.79)$ & $2(16)$ & $2(20)$ & 17.9 & $2(19.20)$ & 18.38 \\
\hline USA & 23 & $3(10.80)$ & 8.04 & $4(10.16)$ & $2(16)$ & $4(10)$ & 7.95 & $3(10.95)$ & 6.18 \\
\hline Turkey & 21 & $4(9.86)$ & 5.1 & $3(10.70)$ & $4(4)$ & $3(10.5)$ & 5 & $4(9.95)$ & 5.25 \\
\hline England & 12 & $5(5.63)$ & 12.42 & $6(4.28)$ & $2(16)$ & $6(4.5)$ & 12.89 & $5(5.47)$ & 13.45 \\
\hline Pakistan & 12 & $5(5.63)$ & 4.42 & $5(4.81)$ & $3(8)$ & $5(5)$ & 4.3 & $5(5.47)$ & 4.18 \\
\hline India & 8 & $6(3.76)$ & 4.75 & $6(4.28)$ & 0 & $7(4)$ & 4.75 & $6(3.98)$ & 4.75 \\
\hline Japan & 8 & $6(3.76)$ & 10.75 & $7(3.74)$ & $4(4)$ & $8(3.5)$ & 12 & $6(3.98)$ & 10.75 \\
\hline Russia & 5 & $7(2.35)$ & 1.4 & $8(2.14)$ & $4(4)$ & $10(2)$ & 1 & $7(2.49)$ & 1.4 \\
\hline Slovenia & 5 & $7(2.35)$ & 13 & $8(2.14)$ & $4(4)$ & $9(2.5)$ & 13 & $8(91.99)$ & 15.5 \\
\hline
\end{tabular}

TP: total number of articles; TPR (\%): rank of the total number of articles and percentage; IPR (\%): rank of single country articles and percentage in all single country articles; $C P R(\%)$ : rank of internationally collaborative articles and percentage in all internationally collaborative articles; FPR (\%): rank of first-author articles and percentage in all first-author articles; $R P R(\%)$ : rank of corresponding-author articles and percentage in all corresponding-author articles; $C P P_{2020}$ : number of citations $\left(T C_{2020}\right)$ per publication $(T P)$. 
Spain with two articles ranked 12th was the top productive country and Belgium, Hungry, Saudi Arabia, Germany, Sweden, Sri Lanka, Uzbekistan, Israel, Canada, and the Netherlands were the countries with one publication each. Five publication indicators were used for the comparison of publication performance: the total number of articles (TP), single-country articles $(I P)$, internationally collaborative articles $(C P)$, first-author articles (FP), and corresponding-author articles (RP) (Hsu and Ho, 2014) as well as their $C P P_{2020}$ (Fu and Ho, 2018).

China dominated among the five publication indicators with a TP of 78 articles (31.97\% of 244 articles), an IP of 71 articles (37.77\% of 188 single-country articles), a CP of seven articles (12.5\% of 56 internationally collaborative articles), an FP of 77 articles (31.56\% of 244 first-author articles), and an $R P$ of two articles $(0.82 \%$ of 244 corresponding-author articles). Compared to the top 10 countries, pigment coloration articles by Egypt had the highest $C P P_{2020}$ of $T P, F P$, and $R P$ with $17.49,17.9$, and 18.38 , respectively. Natl Res Ctr, Text Res Div, Cairo in Egypt published two of the top ten articles as both first author and corresponding author with $C P P_{2020}$ of 74 (rank first) and 58 (rank third). Figure 4 shows a comparison of development trends among the top six leading countries with more than 10 articles. The highest number of articles annually for a country after 2013 was mainly China.

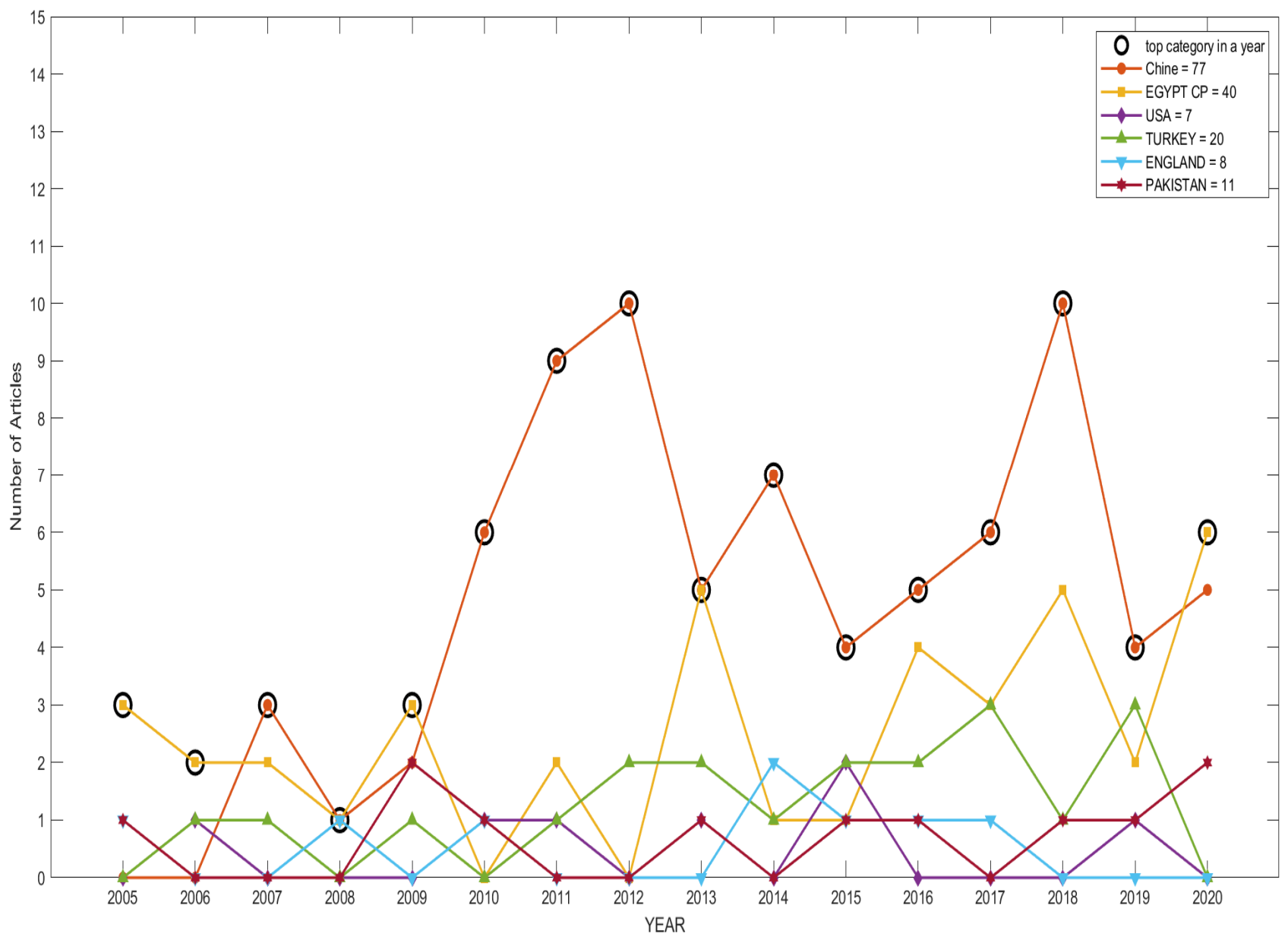

Figure 4. Comparison of the development trends among the top six productive countries with $T P>5$.

In the case of the performance of institutions, 111 articles ( $45.50 \%$ of 244 articles) came from a single institution, while 133 articles (54.5\%) were collaborative amongst institutions. Only six institutes had six articles or more: Natl Res Ctr, Text Res Div, Cairo, (Egypt) with 26 articles (10.66\% of 244 articles), Donghua University (China) with 13 articles (5.33\% of 244 articles), Ege University (Turkey) with eight articles (3.28\%), Helwan University (Egypt) 
with eight articles (3.28\%), Istanbul tech University (Turkey) with six articles (2.46\%), Wuhan Textile University (China) with six articles (2.46\%), and Natl Res Ctr, Text Res Div, Giza (Egypt) with six articles (2.46\%).

Natl Res Ctr, Text Res Div, Cairo also published the most single-institute articles (seven articles; $6.31 \%$ ), inter-institutional articles (14 articles; $10.5 \%$ ), and first-author articles (26 articles; 10.6\%) but did not appear as the corresponding-author in any articles. In addition, there were eight single-author articles (3.28\%) in the pigment coloration study.

\subsection{The Most Frequently Cited Articles}

After publication, highly cited publications may or may not have a high impact or visibility [43]. The number of citations received in the most recent year of $2020\left(C_{2020}\right)$ may offer readers extra information regarding the influence of a highly referenced work today [22]. When the 244 pigment coloration articles were sorted by $T C_{2020}$, a different ranking was generated compared to the ranking obtained from the $C_{2020}$ sorting. A total of 131 articles $(53.69 \%$ of 244 articles) did not receive any citations in the most recent year $\left(C_{2020}=0\right)$, and $53(21.8 \%)$ articles had no citations from their publishing year until the end of $2020\left(T C_{2020}=0\right)$.

Moreover, $58 \%$ of the top $100 C_{2020}$ articles were also among the top $100 T C_{2020}$ articles. The 244 pigment coloration articles were searched with search keywords in their title, abstract, and author keywords. A total of 187 articles (76.64\% of 244 articles), 154 articles (63\% of 244 articles with KeyWord Plus), and 191 articles (78.28\% of 244 articles with author keywords) contained search keywords in their title, abstract, and author keywords, respectively. The title of an article is a label that supplies reasonable details of the article's subjects [44].

Author keywords were given by authors to offer more information about the main research focused on articles. Articles that contain search keywords in their abstract might relate to the search topic less directly. The top two most-frequently cited articles, (Table 4) titled, "Heightened phenotypic variation and age-based fading of ultraviolet butterfly wing coloration" [45] and "Durable antimicrobial cotton textiles modified with inorganic nanoparticles" [46] contained search keywords in their abstract only. These articles do not directly relate to pigment coloration research.

Table 4. The top 10 most-frequently cited articles with search keywords in their title or author keywords.

\begin{tabular}{|c|c|c|c|}
\hline$R\left(T C_{2020}\right)$ & $R\left(C_{2020}\right)$ & Title & Country \\
\hline $1(74)$ & $6(6)$ & $\begin{array}{l}\text { Synthesis of polyurethane acrylate oligomers as aqueous UV-curable binder for inks of } \\
\text { ink jet in textile printing and pigment dyeing }\end{array}$ & Egypt \\
\hline $2(60)$ & $4(8)$ & Durable antimicrobial cotton textiles modified with inorganic nanoparticles & China \\
\hline $3(58)$ & $7(5)$ & Development of ecofriendly binders for pigment printing of all types of textile fabrics & Egypt \\
\hline $4(54)$ & $2(15)$ & $\begin{array}{l}\text { Smart textile framework: Photochromic and fluorescent cellulosic fabric printed by } \\
\text { strontium aluminate pigment }\end{array}$ & Egypt \\
\hline $5(51)$ & $5(7)$ & Eco-friendly printing of natural fabrics using natural dyes from alkanet and rhubarb & Egypt \\
\hline $6(49)$ & $9(2)$ & $\begin{array}{l}\text { Heightened phenotypic variation and age-based fading of ultraviolet butterfly } \\
\text { wing coloration }\end{array}$ & USA, Sweden \\
\hline $6(49)$ & $8(3)$ & The application of chitosan in pigment printing & England \\
\hline $8(45)$ & $8(3)$ & Combined antimicrobial finishing and pigment printing of cotton/polyester blends & Egypt \\
\hline $9(43)$ & $5(7)$ & $\begin{array}{l}\text { Effect of plasma superficial treatments on antibacterial functionalization and coloration } \\
\text { of cellulosic fabrics }\end{array}$ & Egypt \\
\hline $10(41)$ & $1(17)$ & $\begin{array}{l}\text { Development of green waterborne UV-curable vegetable oil-based urethane acrylate } \\
\text { pigment prints adhesive: Preparation and application }\end{array}$ & China \\
\hline $19(25)$ & $3(10)$ & $\begin{array}{l}\text { Preparation of epoxy-acrylate copolymer/nano-silica via Pickering emulsion } \\
\text { polymerization and its application as printing binder }\end{array}$ & China \\
\hline
\end{tabular}


Figure 5 shows the citation trends of the top seven most often cited articles with search keywords in the title or author keywords. An article by Kemp [45] ranked sixth on $T_{2020}$ with 49 but ranked ninth on $C_{2020}$ with 2. Similarly, an article by Gao et al. [47] ranked 19th on $T C_{2020}$ with 25 but ranked third on $C_{2020}$ with 10 . An article entitled "Synthesis of polyurethane acrylate oligomers as aqueous UV-curable binder for inks of ink jet in textile printing and pigment dyeing" by El-Molla et al. [33] from Egypt ranked top ten in both $T C_{2020}$ and $C_{2020}$ with 74 (rank first) and 40 (rank sixth), respectively.

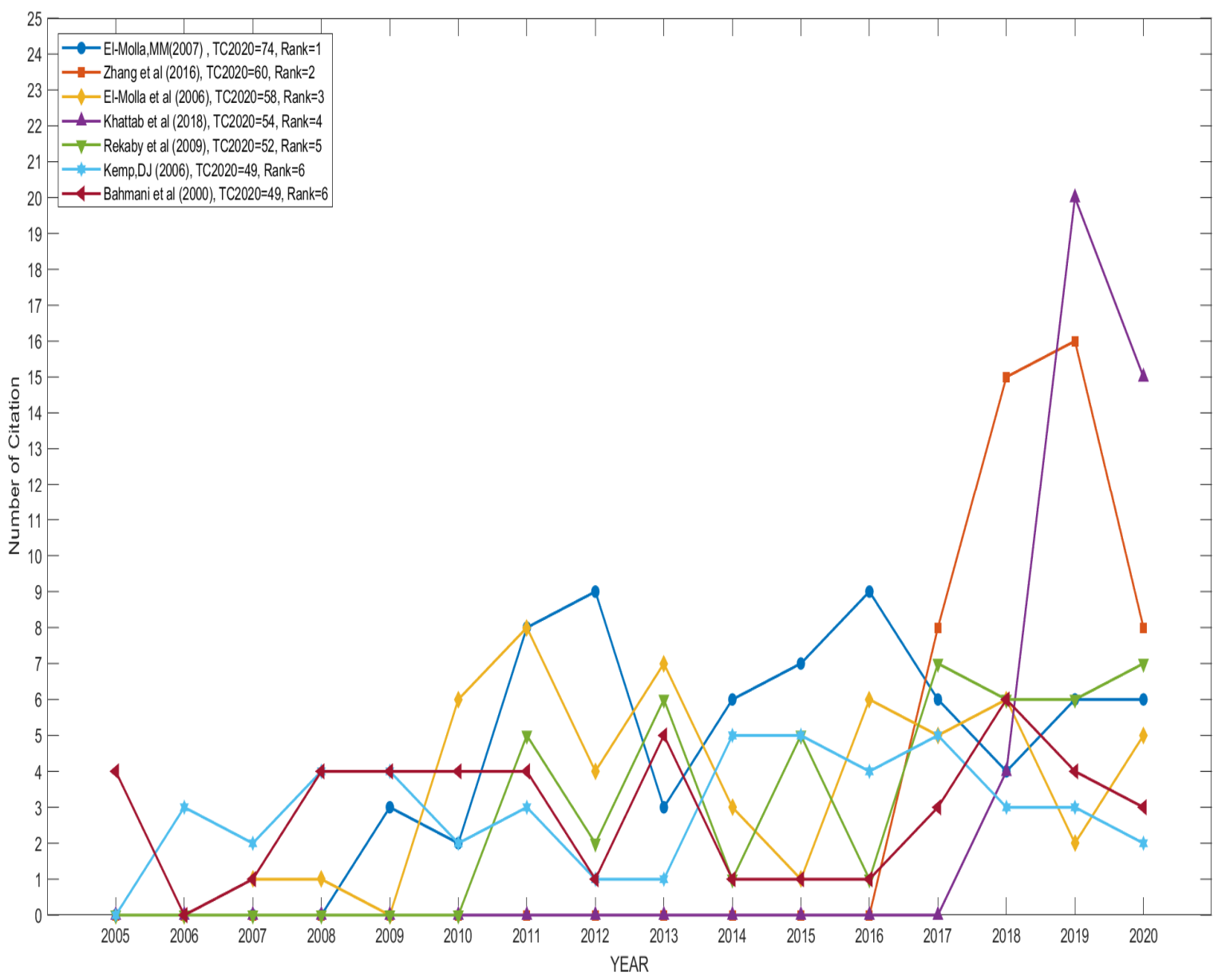

Figure 5. The citation histories of the top seven most-frequently cited articles with search keywords in their title or author keywords $\left(T C_{2020}>45\right)$.

\section{Discussion}

Analyses of the used words in publication titles, abstracts, author keywords, and KeyWords Plus were proposed for the research focuses [48]. In SCI-EXPANDED, 191 (78.28\% of 244 publications) and 154 (63\%) pigment coloration articles contained author keywords and KeyWords Plus information, respectively. Table 5 shows the top 20 mostused words provided in each of the article titles, author keywords, and KeyWords Plus. Except for search keywords, a total of 58 articles (23.78\% of 244 articles), 43 articles (22.5\% of 191 articles with author keyword information), and 11 articles (7.14\% of 154 articles with KeyWords Plus information) contained 'pigment', 'printing' and 'cotton' as the most-used words, respectively. 
Table 5. The top 20 most-used words in the title, abstract, author keywords, and KeyWords Plus.

\begin{tabular}{|c|c|c|c|c|c|c|c|c|c|c|c|}
\hline $\begin{array}{l}\text { Word in } \\
\text { Title }\end{array}$ & $T P$ & $R(\%)$ & $\begin{array}{l}\text { Word in } \\
\text { Abstract }\end{array}$ & $T P$ & R (\%) & $\begin{array}{c}\text { Author } \\
\text { Keywords }\end{array}$ & $T P$ & $R(\%)$ & $\begin{array}{c}\text { KeyWords } \\
\text { Plus }\end{array}$ & $T P$ & $R(\%)$ \\
\hline Pigment & 170 & $2(19.4)$ & Pigment & 676 & $1(15.5)$ & Pigment & 149 & $1(20.9)$ & Cotton & 31 & $1(6.9)$ \\
\hline Printing & 117 & $4(13.3)$ & Printing & 471 & $2(10.8)$ & Printing & 98 & $2(13.7)$ & Fabrics & 25 & $2(5.5)$ \\
\hline Fabrics & 91 & $8(10.4)$ & Fabric & 465 & $3(10.7)$ & Dyeing & 59 & $3(8.3)$ & Polymerization & 24 & $3(5.3)$ \\
\hline Cotton & 54 & $9(6.2)$ & Color & 342 & $4(7.9)$ & Cotton & 49 & $4(6.9)$ & Dyes & 22 & $5(4.9)$ \\
\hline Dyeing & 52 & $10(5.9)$ & Dyeing & 257 & $5(5.9)$ & Fabric & 45 & $5(6.3)$ & Pigment & 17 & $6(3.8)$ \\
\hline Textiles & 42 & $13(4.8)$ & Fastness & 242 & $6(5.6)$ & Color & 33 & $6(4.6)$ & Nanoparticles & 17 & $7(3.8)$ \\
\hline Color & 31 & $15(3.5)$ & Cotton & 202 & $8(4.6)$ & Binder & 26 & $7(3.6)$ & Color & 16 & $8(3.5)$ \\
\hline Binder & 27 & $19(3.1)$ & Binder & 180 & $10(4.1)$ & Textiles & 19 & $8(2.7)$ & Acid & 16 & $9(3.5)$ \\
\hline UV & 23 & $20(2.6)$ & UV & 112 & $12(2.6)$ & Polyester & 17 & $10(2.4)$ & Fiber & 14 & $10(3.1)$ \\
\hline Synthesis & 21 & $22(2.4)$ & Textiles & 111 & $13(2.5)$ & Cellulose & 17 & $11(2.4)$ & Emulsion & 13 & $12(2.9)$ \\
\hline Cellulose & 18 & $26(2.1)$ & Acrylate & 91 & $17(2.1)$ & Fastness & 16 & $12(2.2)$ & Textiles & 10 & $13(2.2)$ \\
\hline Acrylate & 17 & $27(1.9)$ & Emulsion & 87 & $19(2.0)$ & Emulsion & 16 & $13(2.2)$ & Encapsulation & 9 & $16(2.0)$ \\
\hline Polyester & 15 & $28(1.7)$ & Light & 82 & $23(1.9)$ & UV & 15 & $14(2.1)$ & Antibacterial & 9 & $17(2.0)$ \\
\hline Plasma & 12 & $33(1.4)$ & Polyester & 62 & $34(1.4)$ & Plasma & 14 & $16(2.0)$ & UV & 9 & $19(2.0)$ \\
\hline Fastness & 12 & $37(1.4)$ & Plasma & 54 & $44(1.2)$ & Polymerization & 14 & $17(2.0)$ & Polyester & 8 & $20(1.8)$ \\
\hline
\end{tabular}

$T P$ : number of publications including the word in their title, author keywords, and KeyWords Plus; $R$ (\%): rank of words used and percentage in the title, author keywords, and KeyWords Plus.

The five possible research hotspots of pigment coloration research were "pigment printing", "pigment dyeing", "binder and fastness improvement", "surface modification for pigment coloration", and "nanotechnology in pigment coloration". Each word cluster consists of several supporting words obtained from word analysis.

\subsection{Pigment Printing}

Word analysis revealed that pigment printing is still the center of research in the textiles area, and this is growing day by day. Initially, pigment printing in textiles research was primarily focused on enacting a fundamental theoretical understanding of pigment printing in practice. Methods of application with pigmenting chemistry and the essentiality of a binder were investigated in the beginning. The economic advantages of pigment printing along with other benefits, such as the availability of a wide range of colors that provide a high level of lightfastness properties, were presented to dyers and the colorist community.

At the same time, certain limitations of pigment printing were also discussed. For instance, fastness to dry-cleaning with solvent and abrasion was subpar compared to the standard method [1]. In 1995, pigment printing research focused mostly on how to increase printing quality. Two softeners were used to improve the hand feel of the printed substrate. One softener was based on esters of fatty acids, and another was based on silicon microemulsion. The increase of water absorption was due to the esters of fatty acid-based softeners, whereas improved elasticity came from the incorporation of silicon microemulsion-based softeners, which was ultimately reflected in the fabric hand [49].

Pigment printing was attempted on a dark cloth background with an opacifier to aid in covering up the dark background [50]. The brightness of pigments was shown to be diminished, owing to the usage of titanium dioxide as the opacifier. Diatomaceous earth was later demonstrated to be a worthy opacifier, since it was able to disguise the dark background without lowering the pigment printing color intensity. The pigment concentration also has a role in improving the color strength of the printing paste (red pigment), in which titanium dioxide is utilized as an opacifier (Figure 6). 


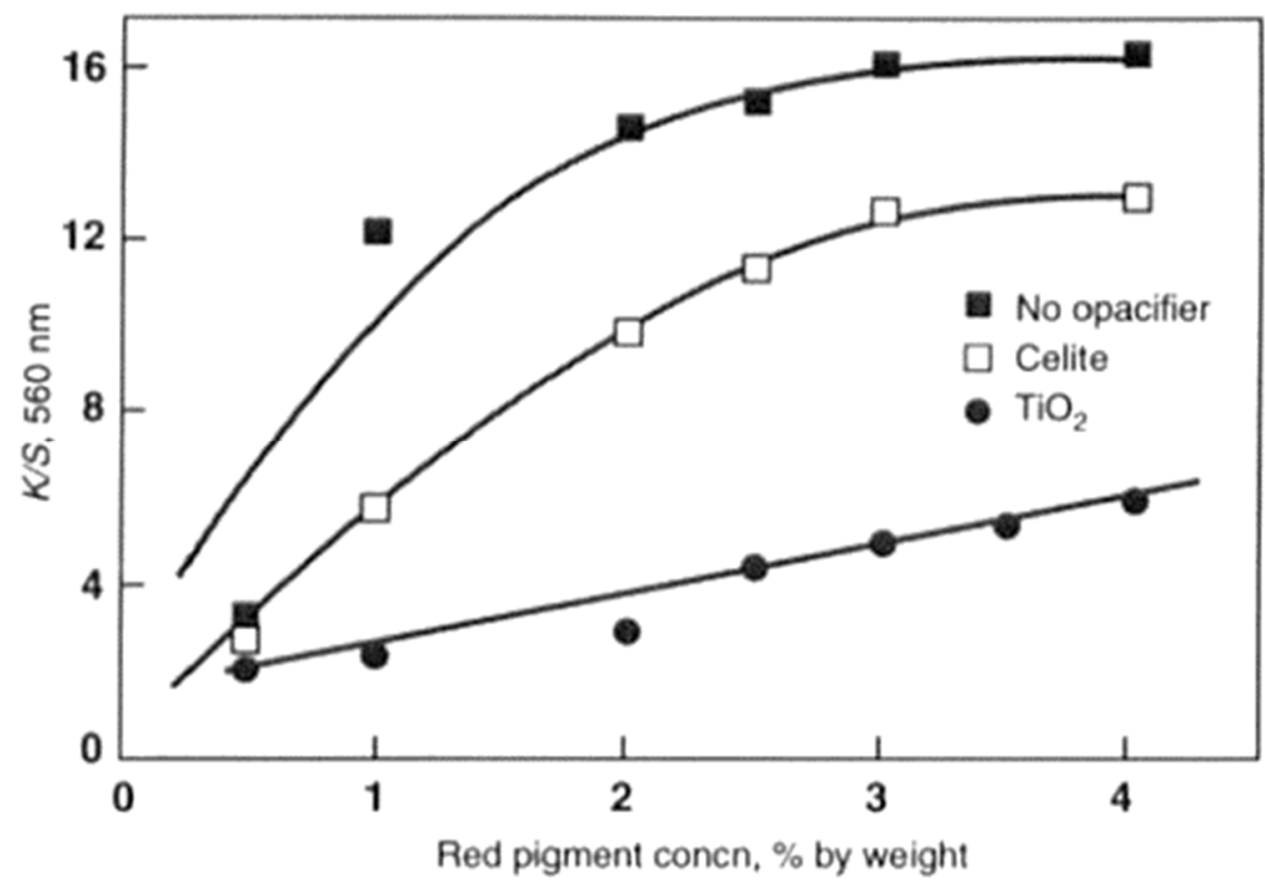

Figure 6. Color strength $(\mathrm{K} / \mathrm{S}, 560 \mathrm{~nm})$ when printing with a non-opacified and with opacified red-pigmented pastes (Reprinted from [50] with permission from Wiley).

Three series of pastes were generated and printed on standard striped cloth, formulated with the binder, thickener, and $0.54 \%$ (on the weight of paste) of red pigment. The first series contained no opacifier and color strength as expressed by the Kubelka-Munk function $\mathrm{K} / \mathrm{S}$, was measured at $560 \mathrm{~nm}$ against the background. The second and the third series were opacified with $15 \%$ Celite 499 and with $15 \% \mathrm{EOz}$ (TR92) on the weight of paste, respectively, and their color strengths were estimated on the dark background also using the Kubelka-Munk function at $560 \mathrm{~nm}$. On the other hand, color strength was found to be increased with pigment concentration when the red-pigmented paste was applied on a white background even without using an opacifier [50].

The next year (1998), several pigment printing studies were conducted. The influence of UV laser treatment on the adhesive qualities of PET and polyamide fibers in pigment printing [51] was one of them. In the year 2000, studies on pigment printing thickeners and binders were published. Bahmani et al. [52] applied chitosan as an ingredient of a combined thickener and binder on polyester and PC woven fabrics, and the outcome was a mixed result. Colorfastness results were found to be satisfactory; however, the color yield and fabric handle were found to be unsatisfactory [52].

Another approach was tested for pigment printing by using a non-polymeric cationic reagent on cotton fabric to make it positively charged, and an improvement in wash fastness was observed [53].

Around the year 2005, several pigment printing technologies began to emerge. ElNaggar et al. developed a method where electron-beam irradiation was applied for pigment printing and later compared with the traditional thermal printing approach. Cotton textiles printed with electron beams showed a higher color strength than those printed using thermal curing techniques. This method also had improved mechanical qualities, durability, and crease recovery [54].

In the next four to five years, pigment printing research yielded new approaches, including advanced and environment-friendly techniques. In 2011, core-shell latex was employed as a binder in an enhanced pigment-printing process. The core of latex particles was formed by the use of hydroxyl-containing poly (dimethylsiloxane) (PDMS-OH). Among the colorfastness properties, good rubbing fastness was achieved. At the same time, soft handle properties were another achievement of that research work [5]. 
Later in 2016, a new approach combining Aloe vera gel and sodium alginate as a thickening agent for printed cotton textiles was introduced. In comparison to the typical synthetic thickening system, the effect was not that spectacular. Excellent rubbing fastness and fabric hand characteristics were among the good outcomes. The color yield, on the other hand, was somewhat reduced [55].

Modified materials have been employed to increase the quality of printing techniques and substrates in recent years. In 2020, poly (methyl vinylsiloxane) with vinyl component was employed instead of unmodified polyacrylate glue as a printing paste, which showed excellent wet rubbing fastness and soft handle [56]. After examining all of the trends from 1990 to 2020, it is apparent that pigment printing is continually gaining popularity. In the future, pigment printing will undoubtedly see additional advancements and innovations.

\subsection{Pigment Dyeing}

Like pigment printing, pigment dyeing is another area of interest for researchers. Although there are various dyes for dyeing, the use of pigments for dyeing has expanded due to the beneficiary features of pigment materials. Cotton, a linear polymer of $1,4 \beta$ glucan, is the most copious polymer available worldwide [57] and is preferred as a pigment dyeing substrate. The earliest investigation on pigment dyeing described the process difficulties of pigment dyeing with cotton. They also discussed the color fastness grades obtained for dyeing with pigments as well as the appropriate machine required for dyeing along with the advantages.

For example, light fastness was found to be good with a rating of about 5-7, whereas rubbing fastness was not up to the mark at 3 for dry rubbing and 2-3 for wet rubbing fastness [58]. Later on, researchers brought up the challenge of pigment dyeing ready-made clothing. Challenges, including proper dye penetration, tight seams, color differences between sewing threads and garment materials, and dyeing durable press-finished clothes were investigated. This is why pigment dyeing was assumed to be more suited than conventional dyeing [1].

Over time, a better kind of pigment dyeing emerged. Fe (III)-oxide pigments were used to color cellulosic fiber textiles, where insoluble iron complexes develop inside the fibers. As a result, a binder was not required to fix the pigment in the cellulose substrate, and dyeing with the pigment yielded outstanding fastness qualities. The lightfastness and wet fastness achieved had ratings of 7-8 and 5, respectively [59].

A new approach was developed in pigment dyeing where the researchers focused on cationizing the cotton fabrics. Cotton textiles were cationized using polyamide-epichlorohydrin. The effects of various cationization conditions on the color strength of modified pigmentdyed cotton textiles, such as the polyamide-epichlorohydrin concentration, duration, $\mathrm{pH}$, and temperature, were studied, and the color strength was found to be satisfactory. The best results were achieved when the cationizing of cotton fabrics was performed at $80{ }^{\circ} \mathrm{C}$ for $20 \mathrm{~min}$ [60].

Another work on cationic modification was done by the team of $\mathrm{Wu}, \mathrm{Y}$., where a cationic modifier was applied for pigment dyeing. The effects of duration, temperature, bath ratio, and $\mathrm{NaOH}$ on the color strength (K/S value) were concisely described. The suggested conditions for obtaining excellent fabric dyeing depth were $5 \mathrm{~g} / \mathrm{L}$ modifier, $8 \mathrm{~g} / \mathrm{L} \mathrm{NaOH}$, and a 40:1 bath ratio. A modification time of $55 \mathrm{~min}$ and a temperature of $70{ }^{\circ} \mathrm{C}$ were recommended [7].

The trends of pigment dyeing research have included not only the dyeing process or method but also the effects of other treatments on pigment dyeing. In 2016, for instance, a study was conducted on the enzymatic treatment of cotton fibers, and the impact of this processing on dyeing qualities as well as the physical and chemical properties of pigments were investigated. Dyeing was conducted with pigment particles that were $120 \mathrm{~nm}$ in size. A comparison of dye absorption between the untreated sample and the cellulase-treated sample revealed that the cellulase-treated cotton had improved dye absorption and had a greater color depth (Figure 7) [61]. 

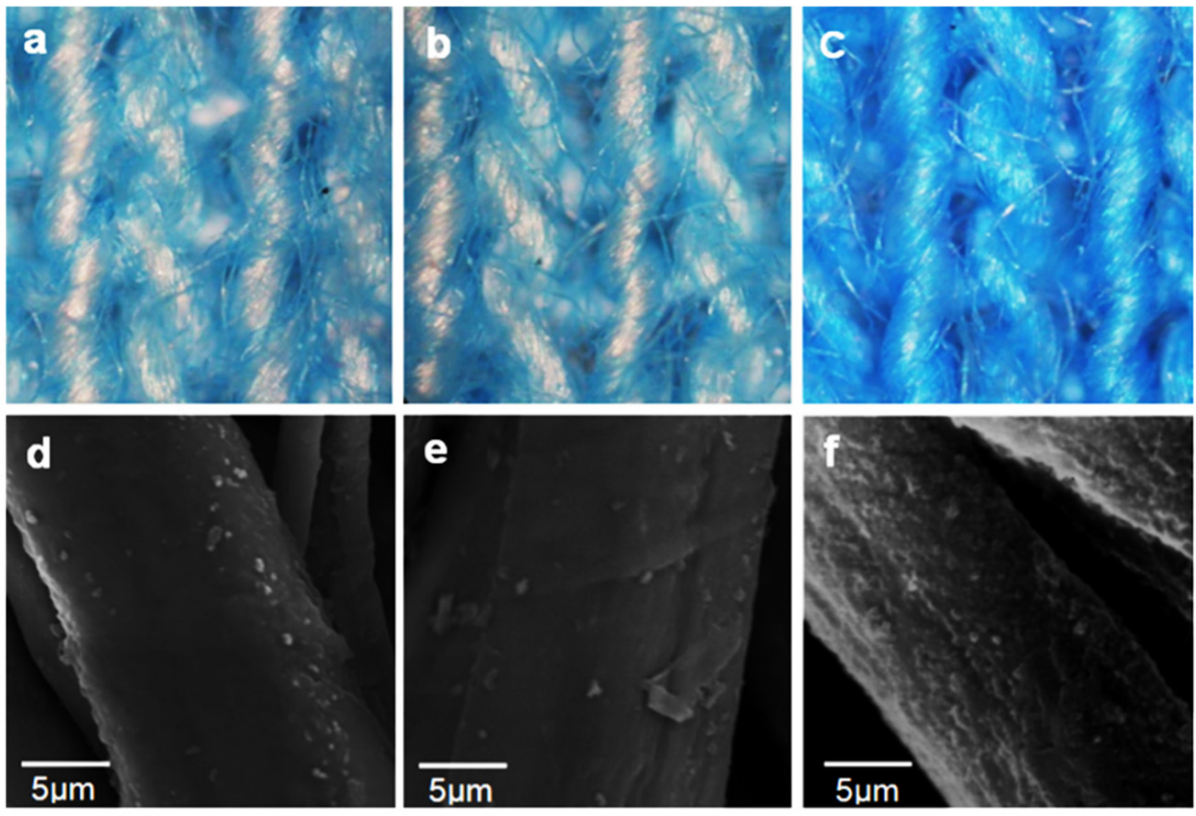

Figure 7. Digital photos of (a) untreated (b) cellulase-free, and (c) cellulase-on-cotton after pigment dyeing and SEM images of (d) untreated, (e) cellulase-free, and (f) cellulase-on-cotton after pigment dyeing (Reprinted from [61] with permission from Springer Nature).

Pigment dyeing research has progressed to a new level in recent years. Pigment dyeing currently employs complex ideas. In one of the approaches, fluorescent pigment latex was encapsulated by poly-methyl methacrylate-co-butyl acrylate and active dispersant (CI Solvent Yellow-43) to create cationized cotton fabric at $80{ }^{\circ} \mathrm{C}$ for $50 \mathrm{~min}$ where the $\mathrm{pH}$ was maintained at 7 in the dyebath. The adsorption kinetics data suggested that the chemical sorption is a rate-limiting step, rather than the mass transfer [62]. Thus, different advanced modifications for pigment dyeing were found by analyzing the research trends. The most startling finding was that the majority of pigment dyeing research was done on cotton substrates. This may indicate the possibility of future work on pigment dyeing on non-cellulosic substrates.

\subsection{Binder and Fastness Improvement}

A binder is one of the most significant ingredients of pigment coloration, as pigment application without a binder is difficult to imagine. The fastness properties of pigmentcolored material directly depend on the type and quality of the binder. This is why researchers are concerned about the quality of the binder and how it can be improved, as the quality of colored textiles mostly is evaluated by the colorfastness properties of that colored textile. Most of the binder-related research up to 2020 is about binder modification by using different materials or methods and the subsequent evaluation of the fastness properties.

Early research focused on the binder chemistry, the crosslinking mechanism of the binder with the surface of textile substrate, and the selection of binders for different textile fibers. Different binders were found to be suitable for different fibers, such as cotton and polypropylene. [1]. As it is known that the crock fastness properties of pigment application are not satisfactory, importance was given to the research for improving the crock fastness. One such work was to assess the effect of the binder and finishing method (pre and post) on the crock fastness results of two types of fabric, where one was cotton and another one was an $80 / 20$ polyester/cotton blend.

Acrylic and butadiene acrylonitrile were the two binders used in the experiment. Poor wet rubbing fastness was found for prefinished polyester/cotton blended fabric in the case of both binders, whereas the dry crock fastness results were slightly better for pre-finished fabric with an acrylic binder. To overcome that issue, a non-formaldehyde system was 
applied both for pre-finishing and post-finishing, and this showed improved results. The post-finished polyester/cotton blended fabric and 100\% cotton fabric showed satisfactory results of wet and dry crock fastness for both binders. However, the acrylic binder only showed good dry crock fastness [63].

Gradually researchers moved to eco-friendly binder applications in pigment application to make the process sustainable. For instance, chitosan was used as a combined thickener and binder in the assessment of pigment printing, and a comparison was performed with a commercially used printing system, like Alco print. Appropriate viscosity was observed, and satisfactory prints were achieved on polyester fabrics and polyester/cotton blended fabrics as well; however, drawbacks included the lower color strength and higher stiffness of the fabric [52]. Another work that incorporated eco-friendliness in binder formulation was performed by El-Molla et al. in 2006.

Polyurethane acrylate based on either a polyethylene glycol or glycerol ethoxylateco-propoxylate binder of an aqueous medium was applied in a printing paste. Fastness properties were observed to be good for printed fabrics, and the hand feel of the printed goods was also found to be soft [64]. Researchers' interest grew regarding the preparation of eco-friendly binders or binders from natural resources in this bibliometric analysis.

The team of Abou Taleb et al. utilized environmentally friendly resources, such as Egyptian wool and feathers, to produce nano-keratin-based binders, which were applicable for the pigment printing of various fibers, such as viscose, polyester, polyester/viscose, pure polyacrylic, and polyester/acrylic. The color strength values of printed fabrics using nano-keratin-based binders were similar to those of a commercial binder, and fastness properties with an elevated stiffness were also found to be almost the same [65].

In addition, a new variety of polyurethane acrylate was synthesized to apply as a binder for polyester fabric's pigment printing paste. Three fixation modes, namely thermo fixation, radiation curing in UV, and microwave, were utilized for curing purposes. The color strength results were similar or even higher compared to the commercial binder [66]. Most recently, a more advanced concept was developed where two polyurethane oligomers or terpolymers, named polyurethane acetate vinyl acrylate, were synthesized and applied as binders for pigment printing on cotton fabrics. Enhanced rubbing fastness with improved color strength and fastness to washing were observed when compared with commercial binders [67].

\subsection{Surface Modification for Pigment Coloration}

Although pigment printing and dyeing were the major focuses in the published scholarly documents during the last three decades, when evaluating research trends, another topic was identified, namely surface modification for pigment coloration. Surface modification is well established in many research fields of textiles, including extreme fiber dyeing [68], apparel finishing [69], flame retardant finishes [70], and UV finishes [71]. Modern technologies are employed to change the surface of textile substrates in pigment printing and dyeing processes.

The earliest mention of surface modification was reported by Doblies et al. in 1998, where the effects of UV laser treatment on the adhesion qualities of PET and polyamide fibers in pigment printing were investigated. Using laser action for increasing the adhesion qualities connected with surface modification was explained in this investigation [51]. The use of UV-curable binders for pigment coloration has been studied on cotton, polyester/cotton, and polyester textiles, and no surface modification was required.

The results were satisfactory because the use of UV resins and UV curing processes improved the color fastness and feel properties [72]. Later, pigments were used to dye cotton garments into dark shades via plasma treatment. Plasma-treated cotton fabrics have a significantly better color yield, level dyed surface, and rubbing fastness when compared to untreated cotton fabrics [73].

Another innovative idea was to employ corona discharge, a sort of atmospheric plasma, to modify the surface of three different types of textiles (polyester, polyamide, and 
polypropylene fiber fabrics). The success of the initial treatment of textiles with corona discharge was proven as the pigment print quality was improved [74]. A recent laser-induced surface modification on denim fabric was reported by Tse and Kan in 2020. One of the goals was to test the comfort of laser-treated pigment-printed denim textiles. The denim samples' surface characteristics were found to be unaffected by laser treatment or pigment printing, which demonstrated the low-stress mechanical qualities of laser treatment. Smooth and even surfaces of the treated samples were observed after evaluation [75].

\subsection{Nanotechnology in Pigment Coloration}

The use of nanoparticles to increase the coloring capabilities of pigments has received attention from textile researchers. Nanoparticles were even tested as an alternative to pigments. The first research on the use of nanoparticles for textile coloration was published in 2003. Nanoparticles with a size of $8 \mathrm{~nm}$ were applied on polyester and acrylic textiles as an alternative of pigment at $180{ }^{\circ} \mathrm{C}$ with cationic dispersant. A successful coloration was observed [76]. Nanoparticles were used along with a binder to provide additional properties to the colored substrate, such as antimicrobial characteristics. Silk textiles were successfully dyed and printed by pigment, where $\mathrm{TiO}_{2}$ nanoparticles were applied in combination with the binder. The incorporation of $\mathrm{TiO}_{2}$ nanoparticles in the coloration process yielded improved antibacterial characteristics, UV protection, and anti-wrinkle qualities [77].

Current nanotechnology research developments have enabled the production of nanofibers in textile research, such as electrospinning technology for the production of nanofibrous mat [78]. One such work was the pigment coloration of cellulose nanofibers. Regenerated cellulose, i.e., cellulose acetate was electrospun followed by treatment with $\mathrm{NaOH}$ to develop nanofibrous mats. These mats were then subjected to pigment coloration using a commercial pigment with the help of the pad-dry-bake method. Excellent color strength, light, and wash fastness were achieved [79].

After reviewing the majority of publications, it is clear that the use of nanoparticles in pigment coloring is highly successful. Different plasma, ultraviolet, and laser treatments have also been employed to develop the surface features of pigment-colored or printed fabrics. Future researchers will undoubtedly investigate these new technologies to deliver more valuable work in the field of textile research. Other than nanotechnology, biotechnology has also been applied in pigmenting natural fibers, such as cotton. This naturally colored cotton was found to possess superior radical scavenging properties [80].

\section{Conclusions}

In this work, we discussed some of the worldwide research trends in pigment coloration by examining the bibliometric information accessible in the titles, keywords, keyword additions, author keywords, and author performance of highly cited publications published on SCI-EXPANDED from 1990 to 2020. Analysis using supporting words in the title, author, keywords, abstract, and KeyWords Plus was used to locate research focus and research trends.

Pigment coloration research increased sharply during this period. Many studies in 38 Web of Science categories, including polymer science, multidisciplinary material science, applied chemistry, multidisciplinary chemistry, and material science textiles, were performed to develop an ideal solution for improving pigment utilization for various applications. Pigment coloration articles were published mainly in the category of polymer science in the last five years. Articles were published in English with only five exceptions; two articles appeared in Croatian and the others were published in German, Chinese, and Japanese.

Although a single language was dominant in pigment coloration research, the research works were moderately spread across the globe (32 different countries) with international collaborations from 24 different countries. Four Asian countries, two Middle East countries, one American country, one country from the UK, Slovenia, and Russia made the top ten 
list of publications. Two Chinese universities led in the publication of pigment coloration research followed by a university from Portugal, whereas Kyoto University in Japan had the highest $C P P_{2020}$ (609).

Five important future research hotspots of pigment coloration were identified. After reviewing those publications, it is clear that, as predicted, the printing and dyeing of textiles by pigment were the main two research hotspots. Traditionally, pigment printing has been widely practiced, and therefore research has evolved around pigment printing. Pigment dyeing emerged as a competitive candidate in the field of pigment coloration.

Interestingly, cotton and polyester were the most-used fiber types as raw materials for pigment coloration in the last three decades. These fabrics were the most common forms of textile materials used for the experimental work of coloring them. Most of the research successes were achieved for cellulosic textile materials. Perhaps researchers will now concentrate on synthetic material in upcoming studies. Fastness properties were the most studied characteristics of the colored substrates with pigment during this studied period, which can be realized from the research emphasis on the binder used in pigment coloration.

This trend is expected to remain the same in the future, as a colored substance without proper fastness properties does not have commercial value. Nanotechnology has also been introduced in this research field in the last decade. The use of nanoparticles in pigment coloration was highly successful. Different plasma, ultraviolet, and laser treatments have been employed to develop the surface features of pigment-colored or printed fabrics and to increase the pigment uptake by textile substrates.

Future researchers will undoubtedly investigate these new technologies to deliver more valuable work in the field of textile coloration research. In brief, while numerous study findings have looked at the usage of pigment coloration, further research is needed to determine the feasibility of pigment production, particularly in terms of the cost-effectiveness. As a result, additional pigment coloring applications will be possible, particularly in textile dyeing and printing.

This bibliometric analysis considered articles published only in the Science Citation Index Expanded of Web of Science. Articles published in other databases, such as Scopus can also be explored.

Author Contributions: M.T.I. conceptualized the review topic, extracted data, ran the data analysis, and reviewed and edited the manuscript; M.S.F. and A.A.S. drafted the 'methods' and 'results' sections; F.F. and A.F.M.F.H. drafted the 'introduction' and 'discussion' sections of the manuscript. All authors have read and agreed to the published version of the manuscript.

Funding: This research received no external funding.

Institutional Review Board Statement: Not applicable.

Informed Consent Statement: Not applicable.

Data Availability Statement: The metadata supporting this systematic and bibliometric analysis are from previously reported studies and datasets, which have been cited. The processed data are available from the corresponding author upon request.

Conflicts of Interest: The authors declare no conflict of interest.

\section{References}

1. Aspland, J.R. Pigments as textile colorants-Pigmenting or pigmentation. Text. Chem. Color. 1993, 25, 31-37.

2. Heinz, G.; Robert, R.K. Direct print coloration. In Textile Printing; Miles, L.W.C., Ed.; Society of Dyers and Colourists: Bradford, UK, 2003.

3. Broadbent, A.D. Basic Principles of Textile Coloration; Society of Dyers and Colourists: Bradford, UK, 2001.

4. Schwindt, W.; Faulhaber, G. The Development of Pigment Printing Over the Last 50 Years. Rev. Prog. Color. Relat. Top. 1984, 14, 166-175. [CrossRef]

5. Jiang, X.; Gu, J.; Tian, X.Z.; Huang, D.; Yang, Y.Q. Synthesis of the Hydroxyl-Containing Poly(dimethyl siloxane) Modified Polyacrylate Core-Shell Latex and the Application as a Novel Binder for Pigment Printing of Fabric. J. Dispers. Sci. Technol. 2011, 32, 1266-1272. [CrossRef] 
6. El-Shishtawy, R.M.; Nassar, S.H. Cationic pretreatment of cotton fabric for anionic dye and pigment printing with better fastness properties. Color. Technol. 2002, 118, 115-120. [CrossRef]

7. Wu, Y.; Zhang, Z.Q. Application of Cationic Modification Agent to Pigment Dyeing. Adv. Mater. Res. 2013, 627, 369-373. [CrossRef]

8. Halim, A.F.M.F.; Islam, M.T.; Hoque, M.M.U. Chemistry of sustainable coloration of textile materials. In Green Chemistry for Sustainable Textiles; Ibrahim, N., Hussain, C.M., Eds.; Woodhead Publishing: Sawston, UK, 2021; pp. 57-67. [CrossRef]

9. Hoque, M.T.; Mazumder, N.-U.-S.; Islam, M.T. Enzymatic Wet Processing. In Sustainable Practices in the Textile Industry; Wiley Online Library: Hoboken, NJ, USA, 2021; pp. 87-110. [CrossRef]

10. Islam, M.T. Environment-friendly reactive dyeing process for cotton to substitute dyeing additives. Clean Technol. Environ. Policy 2016, 18, 601-608. [CrossRef]

11. Islam, M.T.; Mazumder, N.-U.-S.; Asaduzzaman, S. Optimization of Vat Dyeing with an Orange Peel Extract Reducing Agent using Response Surface Methodology. AATCC J. Res. 2020, 7, 1-9. [CrossRef]

12. Islam, M.T.; Asaduzzaman, S. Environmentally-Friendly Textile Finishing. In Textiles and Clothing; Wiley Online Library: Hoboken, NJ, USA, 2019; pp. 101-129. [CrossRef]

13. Page, M.J.; McKenzie, J.E.; Bossuyt, P.M.; Boutron, I.; Hoffmann, T.C.; Mulrow, C.D.; Shamseer, L.; Tetzlaff, J.M.; Akl, E.A.; Brennan, S.E.; et al. The PRISMA 2020 statement: An updated guideline for reporting systematic reviews. Int. J. Surg. 2021, 88, 105906. [CrossRef]

14. Ho, Y.S. Comments on "Mapping the scientific research on non-point source pollution: A bibliometric analysis" by Yang et al. (2017). Environ. Sci. Pollut. Res. Int. 2018, 25, 30737-30738. [CrossRef]

15. Ho, Y.S. Comments on: Ye and Zhang (2019) 'visualizing the knowledge structure of medication-adherence research: A bibliometric analysis (1997-2016)', International Journal of Health Planning and Management, 34: 1333-1353. Int. J. Health Plan. Manag. 2021, 36, 1349-1351. [CrossRef]

16. Fu, H.Z.; Wang, M.H.; Ho, Y.S. The most frequently cited adsorption research articles in the Science Citation Index (Expanded). J. Colloid Interface Sci. 2012, 379, 148-156. [CrossRef] [PubMed]

17. Ho, Y.-S. Some comments on: Mao et al. (2018) "Bibliometric analysis of insights into soil remediation" Journal of Soils and Sediments, 18(7): 2520-2534. J. Soils Sediments 2019, 19, 3657-3658. [CrossRef]

18. Garfield, E. KeyWords Plus-ISI's breakthrough retrieval method. 1. Expanding your searching power on current-contents on diskette. Curr. Contents 1990, 32, 5-9.

19. Fu, H.-Z.; Ho, Y.-S. Top cited articles in thermodynamic research. J. Eng. Thermophys. 2015, 24, 68-85. [CrossRef]

20. Ho, Y.-S. A bibliometric analysis of highly cited publications in Web of Science category of emergency medicine. Signa Vitae 2021, $17,11-19$

21. Moher, D.; Liberati, A.; Tetzlaff, J.; Altman, D.G. Preferred reporting items for systematic reviews and meta-analyses: The PRISMA statement. BMJ 2009, 339, b2535. [CrossRef]

22. Ho, Y.-S. Top-cited Articles in Chemical Engineering in Science Citation Index Expanded: A Bibliometric Analysis. Chin. J. Chem. Eng. 2012, 20, 478-488. [CrossRef]

23. Ho, Y.-S. Bibliometric analysis of the journal of orthopaedic research from 1991 to 2018. Orthop. Res. Online J. 2019, 6, 574-584 [CrossRef]

24. Wang, M.-H.; Ho, Y.-S. Research articles and publication trends in environmental sciences from 1998 to 2009. Arch. Environ. Sci. 2011, 5, 1-10.

25. Hsieh, W.-H.; Chiu, W.-T.; Lee, Y.-S.; Ho, Y.-S. Bibliometric analysis of Patent Ductus Arteriosus treatments. Scientometrics 2004, 60, 105-215. [CrossRef]

26. Ho, H.-C.; Ho, Y.-S. Publications in dance field in Arts \& Humanities Citation Index: A bibliometric analysis. Scientometrics 2015, 105, 1031-1040. [CrossRef]

27. Monge-Nájera, J.; Ho, Y.-S. El Salvador publications in the Science Citation Index Expanded: Subjects, authorship, collaboration and citation patterns. Rev. Biol. Trop. 2017, 65, 1428-1436. [CrossRef]

28. Cheung, K.A.; Xie, N.Y.; Yao, Z.Y.; Houston, S.; Newman, S.; Roman-Ramirez, E.R.; Garrison, T.; Fischer, C.; Muros, V.; Prikhodko, S.; et al. Analysis of Samples Excavated from a Royal Tomb in El Zotz: Application of Materials Science Characterization Techniques in Archaeology. In Proceedings of the 12th Archaeological Chemistry Symposium at the Spring American-ChemicalSociety National Meeting, New Orleans, LA, USA, 7-11 April 2013; pp. 397-418.

29. Ho, Y.-S. A bibliometric analysis of highly cited articles in materials science. Curr. Sci. 2014, 107, 1565-1572.

30. Zhang, T.; Zhang, K.R.; Li, T.; Wang, C.X.; Yang, F. Oligomer-in-water emulsion based waterborne UV-curable paints for cotton printing. Pigment Resin Technol. 2014, 43, 293-298. [CrossRef]

31. Baysal, G.; Kalav, B.; Kayaoglu, B.K. The effect of ultraviolet-curable water-borne polyurethane acrylate binder concentration on the printing performance of synthetic leather. Color. Technol. 2019, 135, 111-120. [CrossRef]

32. Long, X.; Huang, J.Z.; Ho, Y.S. A historical review of classic articles in surgery field. Am. J. Surg. 2014, 208, 841-849. [CrossRef]

33. El-Molla, M.M. Synthesis of polyurethane acrylate oligomers as aqueous UV-curable binder for inks of ink jet in textile printing and pigment dyeing. Dye. Pigment. 2007, 74, 371-379. [CrossRef]

34. Usman, M.; Ho, Y.S. A bibliometric study of the Fenton oxidation for soil and water remediation. J. Environ. Manag. 2020, 270, 110886. [CrossRef] 
35. Ho, Y.-S. The top-cited research works in the Science Citation Index Expanded. Scientometrics 2012, 94, 1297-1312. [CrossRef]

36. Ho, Y.-S.; Fahad Halim, A.F.M.; Islam, M.T. The Trend of Bacterial Nanocellulose Research Published in the Science Citation Index Expanded From 2005 to 2020: A Bibliometric Analysis. Front. Bioeng. Biotechnol. 2022, 9, 795341. [CrossRef]

37. Ho, Y.-S.; Fu, H.-Z. Mapping of metal-organic frameworks publications: A bibliometric analysis. Inorg. Chem. Commun. 2016, 73, 174-182. [CrossRef]

38. Zhai, C.; Ho, Y.-S. A Bibliometric Analysis of Distributed Control Publications. Meas. Control 2018, 51, 113-121. [CrossRef]

39. Vega-Arce, M.; Salas, G.; Núñez-Ulloa, G.; Pinto-Cortez, C.; Fernandez, I.T.; Ho, Y.-S. Research performance and trends in child sexual abuse research: A Science Citation Index Expanded-based analysis. Scientometrics 2019, 121, 1505-1525. [CrossRef]

40. Ho, Y.-S.; Wang, M.-H. A bibliometric analysis of artificial intelligence publications from 1991 to 2018. COLLNET J. Scientometr. Inf. Manag. 2021, 14, 369-392. [CrossRef]

41. Rekaby, M.; Salem, A.A.; Nassar, S.H. Eco-friendly printing of natural fabrics using natural dyes from alkanet and rhubarb. J. Text. Inst. 2009, 100, 486-495. [CrossRef]

42. Giannoudis, P.V.; Chloros, G.D.; Ho, Y.S. A historical review and bibliometric analysis of research on fracture nonunion in the last three decades. Int. Orthop. 2021, 45, 1663-1676. [CrossRef]

43. Ho, Y.-S.; Kahn, M. A bibliometric study of highly cited reviews in theScience Citation Index expanded ${ }^{\mathrm{TM}}$. J. Assoc. Inf. Sci. Technol. 2014, 65, 372-385. [CrossRef]

44. Wang, M.-H.; Yu, T.-C.; Ho, Y.-S. A bibliometric analysis of the performance of Water Research. Scientometrics 2010, 84, 813-820. [CrossRef]

45. Kemp, D.J. Heightened phenotypic variation and age-based fading of ultraviolet butterfly wing coloration. Evol. Ecol. Res. 2006, 8, 515-527.

46. Zhang, Y.Y.; Xu, Q.B.; Fu, F.Y.; Liu, X.D. Durable antimicrobial cotton textiles modified with inorganic nanoparticles. Cellulose 2016, 23, 2791-2808. [CrossRef]

47. Gao, D.G.; Chang, R.; Lyu, B.; Ma, J.Z.; Duan, X.Y. Preparation of epoxy-acrylate copolymer/nano-silica via Pickering emulsion polymerization and its application as printing binder. Appl. Surf. Sci. 2018, 435, 195-202. [CrossRef]

48. Zhang, G.; Xie, S.; Ho, Y.-S. A bibliometric analysis of world volatile organic compounds research trends. Scientometrics 2010, 83, 477-492. [CrossRef]

49. ParacOsterman, D.; Dugan, L. Softeners in pigment printing. Tekstil 1995, 44, 355-360.

50. Lahat, Z.; Levene, R.; Zwilchovsky, B.; Marmorash, Y. One-pass pigment printing of bright colours on a dark textile background. J. Soc. Dye. Colour. 1997, 113, 202-205. [CrossRef]

51. Doblies, V.; Kesting, W.; Bossmann, A.; Knittel, D.; Schollmeyer, E. Investigations on adhesion of pigment printings by UV-Laser treatment. J. Prakt. Chem./Chem.-Ztg. 1998, 340, 45-50. [CrossRef]

52. Bahmani, S.A.; East, G.C.; Holme, I. The application of chitosan in pigment printing. J. Soc. Dye. Colour. 2000, 116, 94-99. [CrossRef]

53. Tabba, A.H.; Hauser, P. Effect of cationic pretreatment on pigment printing of cotton fabric. Text. Chem. Color. Am. Dye. Rep. 2000, 32, 30-33.

54. El-Naggar, A.W.M.; Zohdy, M.H.; Said, H.M.; El-Din, M.S.; Noval, D.M. Pigment colors printing on cotton fabrics by surface coating induced by electron beam and thermal curing. Appl. Surf. Sci. 2005, 241, 420-430. [CrossRef]

55. Islam, M.T.; Khan, S.H.; Hasan, M.M. Aloe vera gel: A new thickening agent for pigment printing. Color. Technol. 2016, 132, 255-264. [CrossRef]

56. Zhang, Q.; $\mathrm{Wu}, \mathrm{M}$. Structure of vinyl polysiloxane on properties of polyacrylates film and its pigment printing application. J. Coat. Technol. Res. 2020, 17, 937-948. [CrossRef]

57. Islam, M.T.; Rahman, M.M.; Mazumder, N.-U.-S. Polymers for Textile Production. In Frontiers of Textile Materials; Wiley Online Library: Hoboken, NJ, USA, 2020; pp. 13-59. [CrossRef]

58. Lever, T. Exhaust dyeing with pigments on cotton piece and garments. J. Soc. Dye. Colour. 1992, 108, 477-478. [CrossRef]

59. Kongdee, A.; Bechtold, T. In-fibre formation of $\mathrm{Fe}(\mathrm{OH})_{3}-\mathrm{A}$ new approach to pigment coloration of cellulose fibres. Dye. Pigment. 2004, 60, 137-142. [CrossRef]

60. Fang, K.J.; Zhang, L.B.; Xu, Y.; Zhang, X. Pigment Dyeing of Polyamide-Epichlorohydrin Cationized Cotton Fabrics. J. Appl. Polym. Sci. 2010, 118, 2736-2742. [CrossRef]

61. Hao, L.Y.; Wang, R.; Wang, L.; Fang, K.J.; Liu, J.Q.; Men, Y.J. The influences of enzymatic processing on physico-chemical and pigment dyeing characteristics of cotton fabrics. Cellulose 2016, 23, 929-940. [CrossRef]

62. Li, M.; Zhang, L.P.; Qiu, M.H.; Zhang, Y.; Fu, S.H. Dyeing property of fluorescent pigment latex on cationic knitted cotton fabrics. Text. Res. J. 2019, 89, 422-433. [CrossRef]

63. Hammonds, A.G.; Grimes, M.; Davis, E.; Strouther, M.; Puett, B.; Matkins, K.; Ward, J. Do not let crockfastness rub you the wrong way-A study of the parameters that affect pigment prints. Text. Chem. Color. 1997, 29, 13-15.

64. El-Molla, M.M.; Schneider, R. Development of ecofriendly binders for pigment printing of all types of textile fabrics. Dye. Pigment. 2006, 71, 130-137. [CrossRef]

65. Abou Taleb, M.; Haggag, K.; Mostafa, T.B.; Abou El-Kheir, A.; El-Sayed, H. A novel approach in pigment printing using nano-keratin based binder. Indian J. Fibre Text. Res. 2018, 43, 83-91. 
66. El-Molla, M.M.; Haggag, K.; El-Shall, F.N.; Shaker, N.O.; Alian, N.A. Use of novel synthesized aqueous binders for pigment printing of polyester fabrics. Indian J. Fibre Text. Res. 2013, 38, 57-65.

67. Abdel-Wakil, W.S.; Fahmy, A.; Kamoun, E.A.; Hassan, W.; Abdelhai, F.; Salama, T.M. A New Route for Synthesis of Polyurethanevinyl Acetate Acrylate Emulsions as Binders for Pigment Printing of Cotton Fabrics. Egypt. J. Chem. 2020, 63, 1063-1073. [CrossRef]

68. Islam, M.T.; Aimone, F.; Ferri, A.; Rovero, G. Use of N-methylformanilide as swelling agent for meta-aramid fibers dyeing: Kinetics and equilibrium adsorption of Basic Blue 41. Dye. Pigment. 2015, 113, 554-561. [CrossRef]

69. Islam, M.T.; Rashid, M.R.; Rana, M.R.I. Influence of different chemical treatments on the properties of PC fabric used as lining. Int. J. Cloth. Sci. Technol. 2016, 28, 726-735. [CrossRef]

70. Mazumder, N.-U.-S.; Islam, M.T. Flame Retardant Finish for Textile Fibers. In Innovative and Emerging Technologies for Textile Dyeing and Finishing; Wiley Online Library: Hoboken, NJ, USA, 2021; pp. 373-405. [CrossRef]

71. Alam, I.K.; Moury, N.N.; Islam, M.T. Synthetic and Natural UV Protective Agents for Textile Finishing. In Sustainable Practices in the Textile Industry; Wiley Online Library: Hoboken, NJ, USA, 2021; pp. 207-235. [CrossRef]

72. Li, S.; Boyter, H.; Stewart, N. Ultraviolet (UV) Curing Processes for Textile Coloration. AATCC Rev. 2004, 4, 44-49.

73. Kan, C.W.; Man, W.S. Enhancing Dark Shade Pigment Dyeing of Cotton Fabric Using Plasma Treatment. Coatings 2017, 7, 104. [CrossRef]

74. Brzezinski, S.; Polowinski, S.; Kowalczyk, D.; Malinowska, G. Effect of Corona Discharge Treatment on the Surface Strength and Performance Properties of Synthetic Fibre Textiles. Fibres Text. East. Eur. 2009, 17, 62-68.

75. Tse, S.T.; Kan, C.W. Effect of laser treatment on pigment printing on denim fabric: Low stress mechanical properties. Cellulose 2020, 27, 10385-10405. [CrossRef]

76. Li, D.; Sun, G. Coloration of Polyester and Acrylic Fabrics with Carbon Black Nanoparticles. AATCC Rev. 2003, 3, 19-22.

77. El-Molla, M.M.; El-Khatib, E.M.; El-Gammal, M.S.; Abdel-Fattah, S.H. Nanotechnology to improve coloration and antimicrobial properties of silk fabrics. Indian J. Fibre Text. Res. 2011, 36, 266-271.

78. Islam, M.T.; Laing, R.M.; Wilson, C.A.; McConnell, M.; Ali, M.A. Fabrication and characterization of 3-dimensional electrospun poly(vinyl alcohol)/keratin/chitosan nanofibrous scaffold. Carbohydr. Polym. 2022, 275, 118682. [CrossRef]

79. Ali, S.; Khatri, A.; Baig, U.; Javeed, A.; Rind, N.A. Coloration of cellulose nanofibres with pigments. Color. Technol. 2020, 136, 427-434. [CrossRef]

80. Ma, M.; Hussain, M.; Memon, H.; Zhou, W. Structure of pigment compositions and radical scavenging activity of naturally green-colored cotton fiber. Cellulose 2016, 23, 955-963. [CrossRef] 